\title{
A dynamic oceanographic front drives biogeographical structure in invertebrate settlement along Santa Cruz Island, California, USA
}

\author{
J. Stephen Gosnell ${ }^{1,2, *}$, R. J. A. Macfarlan ${ }^{1,3}$, Nick T. Shears ${ }^{1,4}$, Jennifer E. Caselle ${ }^{1}$ \\ ${ }^{1}$ Marine Science Institute, University of California, Santa Barbara, Santa Barbara, CA 93106, USA \\ ${ }^{2}$ Present address: Coastal and Marine Laboratory, Florida State University, St. Teresa, FL 32358, USA \\ ${ }^{3}$ Present address: Coastal Institute, Department of Natural Resources Science, University of Rhode Island, Kingston, RI 02281, USA \\ ${ }^{4}$ Present address: University of Auckland, Department of Statistics and Leigh Marine Laboratory, Private Bag 92019, \\ Auckland 1142, New Zealand
}

\begin{abstract}
Understanding the factors that determine community diversity is a central focus of ecology and has important implications for conservation and management. We investigated how the local movement of a dynamic front between 2 opposing water masses influenced subtidal invertebrate settlement rates and settlement diversity along the north coastline of Santa Cruz Island, California, USA. Using data from artificial collectors deployed twice per month in 2008 and 2009, we characterized larval settlement of ecologically and commercially important marine invertebrates. We also tracked movement of the front throughout the collection period by analyzing variation in sea temperature at sampling sites. Settlement rates of multiple species of bivalves, gastropods, decapods, and echinoderms were positively associated with the proportion of time a given site spent in a particular water mass. Overall settlement diversity was also related to front location over time, as sites that were exposed to both water masses had higher overall diversity. These results suggest that front movement has a significant impact on settlement and community structure. We also found that these effects applied at several levels of taxonomic resolution, suggesting that our findings are robust to varying levels of identification. Dynamic boundaries may impact overall regional biogeography and community connectivity and lead to communities in the area of front movement having higher levels of diversity. Thus the scale of oceanographic circulation patterns should be considered in conservation and management planning efforts focused on conserving diversity (e.g. the placement of marine protected areas) and in studies of marine population dynamics.
\end{abstract}

KEY WORDS: Biogeographic boundaries · Community diversity · Larval settlement · Temperature fronts - Oceanographic front

Resale or republication not permitted without written consent of the publisher

\section{INTRODUCTION}

Along with local events such as species interactions and disturbance, patterns in species distributions impact community diversity because they influence which organisms can reach, and therefore occupy, a given location (Leibold et al. 2004, O'Connor et al. 2007, Vanschoenwinkel et al. 2007). Because of this, resolution of biogeographic patterns and the mechanisms underlying their establishment and maintenance can increase our understanding of community formation and may also offer important insights for conservation and management efforts (Gaylord \& Gaines 2000, Gaines et al. 2003). Previous work has focused on the impacts of various physical features (e.g. continental divides, rivers, mountain ranges, 
oceanographic circulation patterns) in setting largescale, long-term regional biogeographic boundaries (Cowen et al. 2006, Pelc et al. 2009). A major difference among these features is that while some, such as mountain ranges, may be stable for long periods of time, others, such as oceanographic boundaries and alluvial floodplains commonly formed by flooding rivers, may regularly move or even break down over small temporal and spatial scales. These movement patterns themselves may have important repercussions for spatial and temporal variation in community diversity. For example, changes in river flow can impact the creation of floodplains and connectivity among sites (Ward \& Stanford 1995). For these reasons, determining the relevant temporal and spatial scales over which these boundaries operate may be especially important for communities that exist at the meeting point of major biogeographic breaks.

The scale at which biogeographic boundaries exist and variability in these boundaries may be especially important in marine systems, since these boundaries may greatly influence dispersal and, thus, community connectivity and maintenance (Eckert 2003, Gaines et al. 2009, Watson et al. 2011). Many marine organisms have a bipartite lifecycle, with small, planktonic larvae potentially travelling large distances via transport on ocean currents before metamorphosing to adults that will often inhabit a restricted area for the rest of their lives. The dispersal distances of these larval or juvenile marine organisms can exceed their land-based sedentary counterparts by several orders of magnitude (Kinlan \& Gaines 2003). Although marine larvae of some groups such as fish are capable of directed swimming (Leis \& Carson-Ewart 1997, Fisher et al. 2005), many invertebrates are weaker swimmers, suggesting that transport and connectivity among populations may be greatly impacted by various physical ocean processes depending on the placement of larvae in the water column (Bradbury \& Snelgrove 2001). For example, populations that are geographically distant may share more larvae than expected if they are influenced by the same water mass, or alternatively, geographically proximate locations may share fewer larvae than expected (Bjorkstedt et al. 2002, C. White et al. 2010).

How oceanographic processes such as internal waves, upwelling, and fronts and related environmental correlates such as ocean temperature impact the delivery of marine larvae to reef-based habitat has been studied in the recent past for both fish and invertebrate species (Bjorkstedt et al. 2002, Blanchette et al. 2006, Mace \& Morgan 2006, Broitman et al. 2008, Woodson et al. 2012). Due to limited locomotive ability in many plankton and associated differences in temperature and other factors, fronts may contribute to biogeographic and phylogenetic breaks among populations, species, and communities by limiting dispersal and population connectivity much as mountains or rivers do in terrestrial communities (Gaines et al. 2009, Pelc et al. 2009, Brante et al. 2012). This may be especially true for broadly-dispersing species whose larvae have longer residence times in the water column (Gaines et al. 2009). Fronts may also aggregate larvae from separate regions, leading to the formation of biodiversity 'hotspots' (Wolanski \& Hamner 1988, Belkin et al. 2009, Tittensor et al. 2010). Determining where these boundaries exist may therefore be important to the placement of marine reserves.

However, the role dynamic boundaries between 2 water masses, or moving fronts, play in regulating the diversity of settling marine organisms has been less explored. Fronts can break down or regularly move over small spatial scales, and frontal movement has been shown to impact genetic diversity in a marine fish (Selkoe et al. 2006). Due to the link between circulation patterns and environmental variables such as temperature (Gaines et al. 2009, Tittensor et al. 2010), front movement and the related exposure of sites to different water masses may also contribute to observed relationships between abiotic factors and community structure (McLaughlin et al. 1996, Blanchette et al. 2006, Blanchette \& Gaines 2007, Woodson et al. 2012). Changes in connectivity due to moving biogeographic boundaries may be critical to understanding community diversity. Changes in connectivity may also have implications for management issues such as the design and placement of marine protected areas and networks since the transport of larvae between locations may be essential to maintaining populations (Strathmann et al. 2002, Carr et al. 2003, Gaines et al. 2003, Morgan et al. 2009). Moving boundaries could also contribute to the ability of larvae from source populations to reach sites, and since populations of marine species may differ greatly in responses to environmental factors such as temperature, movement among populations (or lack thereof) may have important repercussions for how populations respond to perturbations such as climate change (Kelly et al. 2012, Sorte et al. 2011, Gleason \& Burton 2013).

To examine the impact of dynamic fronts on larval delivery and diversity, here we focused on larval settlement of several groups of commercially and ecologically important marine invertebrates along the 
north-facing coast of Santa Cruz Island in the Channel Islands, USA (Fig. 1). Rocky reef communities present an excellent system to examine questions concerning biological repercussions of oceanographic forcing (Blanchette et al. 2006, Selkoe et al. 2006, Broitman et al. 2008). These communities are ecologically productive, diverse, and provide important resources for both commercial and recreational user groups (Gunderson et al. 2008). Due to the island's position south-east of Point Conception and its east-to-west orientation, larval delivery along Santa Cruz Island is mediated by 2 opposing ocean currents that dominate the Santa Barbara Channel and that often result in the creation of a dynamic front between the 2 opposing water masses along the island's coast (Hendershott \& Winant 1996, Selkoe et al. 2006). The island's west end is influenced by the California Current which flows south and eastward and typically delivers cold surface water to the Santa Barbara Channel. The eastern end of the island is influenced by the comparatively warmer Southern California Eddy, which runs north and westward into the Channel (Blanchette et al. 2006). The eastward flow of cold water is often forced via upwelling events outside the Santa Barbara Channel, resulting in increased exposure to cold water along the north shore of Santa Cruz Island in the winter and spring (Hickey 1992), while the Southern California Eddy pushes warmer surface water further along the north coast in a westerly direction when upwelling conditions relax in mid- and late summer (Hickey 1992, Harms \& Winant 1998, Oey et al. 2001).

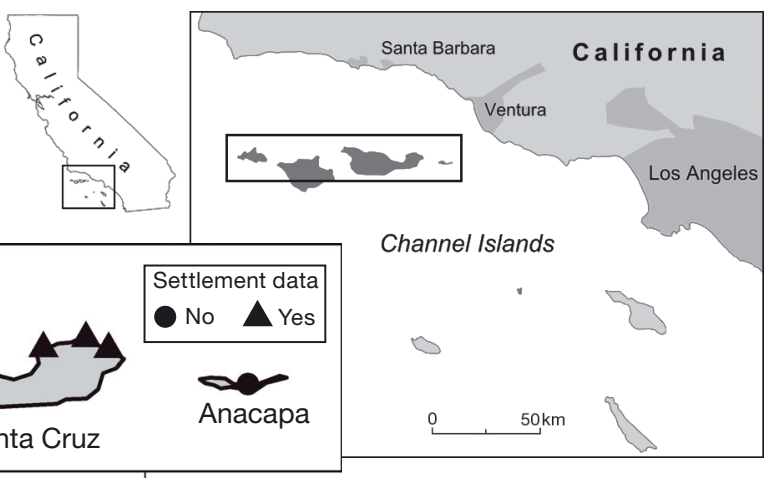

\section{A}
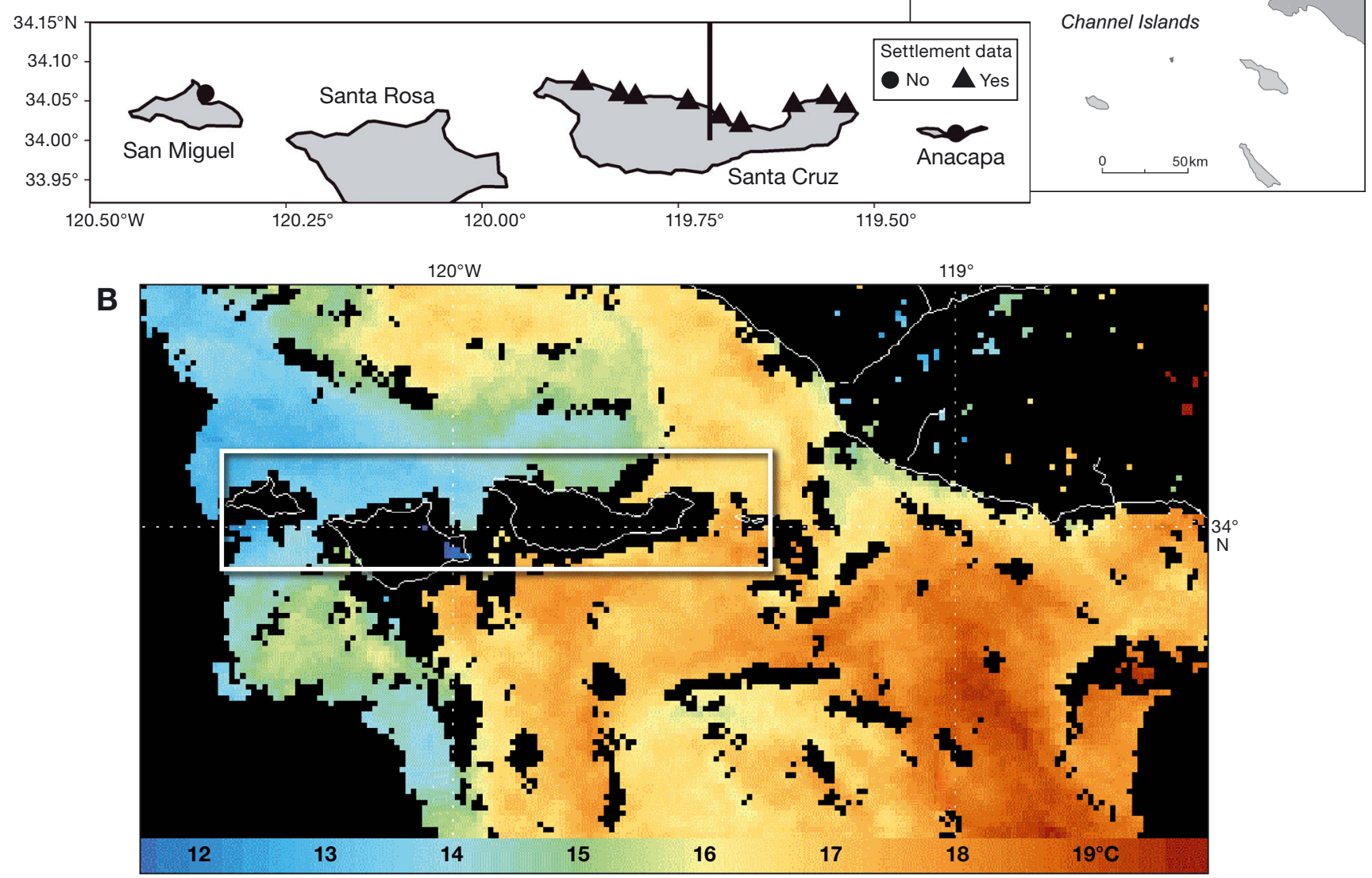

Fig. 1. (A) Location of the Northern Channel Islands and positions of sites on and near Santa Cruz Island, California, USA, where settlement and temperature data were collected. Sites where both settlement and temperature data were collected are marked with triangles, while temperature-only collection sites are marked with circles. Black bar indicates the position where our algorithm for determining front location would assign the front, given temperature data collected within 10 min of the corresponding SST AVHRR image (04:33 h vs. 04:39 h GMT on 10 July 2009), shown in (B). The white box indicates the region enlarged in (A). SST image provided by the Institute for Computational Earth System Science, University of California, Santa Barbara. SST: sea surface temperature; AVHRR: Advanced Very High Resolution Radiometer 
The meeting and movement of these 2 currents results in a longitudinal temperature gradient along the coast that may move both within and between seasons (Fig. 1). Although differential larval settlement has been related to differences in temperature at either end of this temperature gradient (Blanchette et al. 2006), variation in the position of this front over time may also have biological significance. For example, front movement impacts larval delivery and the resulting genetic structure of kelp bass Paralabrax clathratus in the region (Selkoe et al. 2006). Moreover, front movement may provide a mechanism to explain spatial and temporal variation in diversity of species settling out of the plankton and associations with other factors such as temperature. To examine the ability of front movement to explain invertebrate settlement rates and diversity, we monitored changes in sea temperature (to calculate front position) and invertebrate settlement along the north shore of Santa Cruz Island, developed a quantitative method to determine the location of the boundary between water masses, and analyzed relationships between settlement and exposure to each water mass. We also compared the predictive ability of our front position index to other factors commonly associated with settlement patterns, namely temperature and spatial location (longitude).

\section{MATERIALS AND METHODS}

\section{Settlement}

We measured settlement of invertebrates on artificial substrates at 9 sites located along $40 \mathrm{~km}$ of the north shore of Santa Cruz Island in 2008 and 2009 (Fig. 1). We selected sites that spanned the northern coastline of the island and contained rocky reef area adjacent to sand in order to allow boat access. Settlement collectors consisted of wood-handled scrub brushes with polypropylene bristles following previously published methods (Ebert et al. 1994). A pair of brushes was attached approximately 2 to $3 \mathrm{~m}$ below the surface of the water on 3 moorings at each site. Moorings were located adjacent to rocky reefs and kelp forests in water approximately $15 \mathrm{~m}$ deep, and each mooring was a minimum of $100 \mathrm{~m}$ from the next.

We collected brushes roughly twice per month, on the first and third quarter moons for tidal consistency, from late spring to late fall (collection periods: 24 May to 5 November 2008 and 4 April to 19 November 2009). Each pair of brushes was considered 1 replicate sample, resulting in 3 samples per site. Once col- lected, invertebrate larvae were first classified to 4 broader taxonomic groupings (hereafter, supergroups): Echinodermata (Phylum), Decapoda (Order), Bivalvia (Class), and Gastropoda (Class). Where possible, larvae were next classified to lower taxonomic levels (Roesijadi 1976, Carroll \& Winn 1989, Smith \& Johnson 1996). These more-resolved groupings included 18 to species, 6 to genus, 2 to family, 1 to subclass, 1 to infraorder, and 3 to class (Table 1). Since identifying marine invertebrate larvae to species using morphological traits may be time consuming or impossible due to sample condition or the lack of availability of keys or molecular methods, we conducted all analyses when possible at both the supergroup and more-resolved grouping (hereafter, group) level to consider the implications of varying levels of taxonomic identification on our outcomes. Taxonomic sufficiency, or the ability to use higherlevel taxonomic groupings in analyses, has similarly been considered in relation to understanding community-wide diversity for conservation purposes (Timms et al. 2013) or responses to factors such as pollution stress (Chainho et al. 2007) and may offer insight for future work on invertebrate marine taxa.

While most collections were done every $2 \mathrm{wk}$, occasionally collection periods exceeded this period. In order to standardize impacts of exposure time, we first removed data from sample periods in excess of $17 \mathrm{~d}$. All collectors used in the analysis had an average soak time of $14.2 \mathrm{~d}$ (range: 9 to $17 \mathrm{~d}$ ). In order to account for brushes lost during the study and for differences in soak time, daily settlement rates for each collection period for each group were calculated as the total number of settlers collected at the site divided by the number of brush pairs and by the total days between collection and deployment. Settlement rates for analyses are thus defined as the average number of settlers per brush pair per day. Here settlement is defined by the successful delivery of an invertebrate to a larval collector.

We measured water temperature using Tidbit temperature loggers (Onset). Temperature loggers were attached to 1 mooring at each settlement collection site and at the same depth as the larval collectors. In addition, we recorded water temperature at moorings located $14 \mathrm{~km}$ farther to the east (Anacapa Island) and $44 \mathrm{~km}$ to the west (San Miguel Island) of the settlement locations (Fig. 1). Temperature was recorded at 2 min intervals. To remove high-frequency noise from these data, a $1 \mathrm{~h}$ Butterworth low pass filter was then applied. The filtered time series was then interpolated to $20 \mathrm{~min}$ intervals for the collection period. 


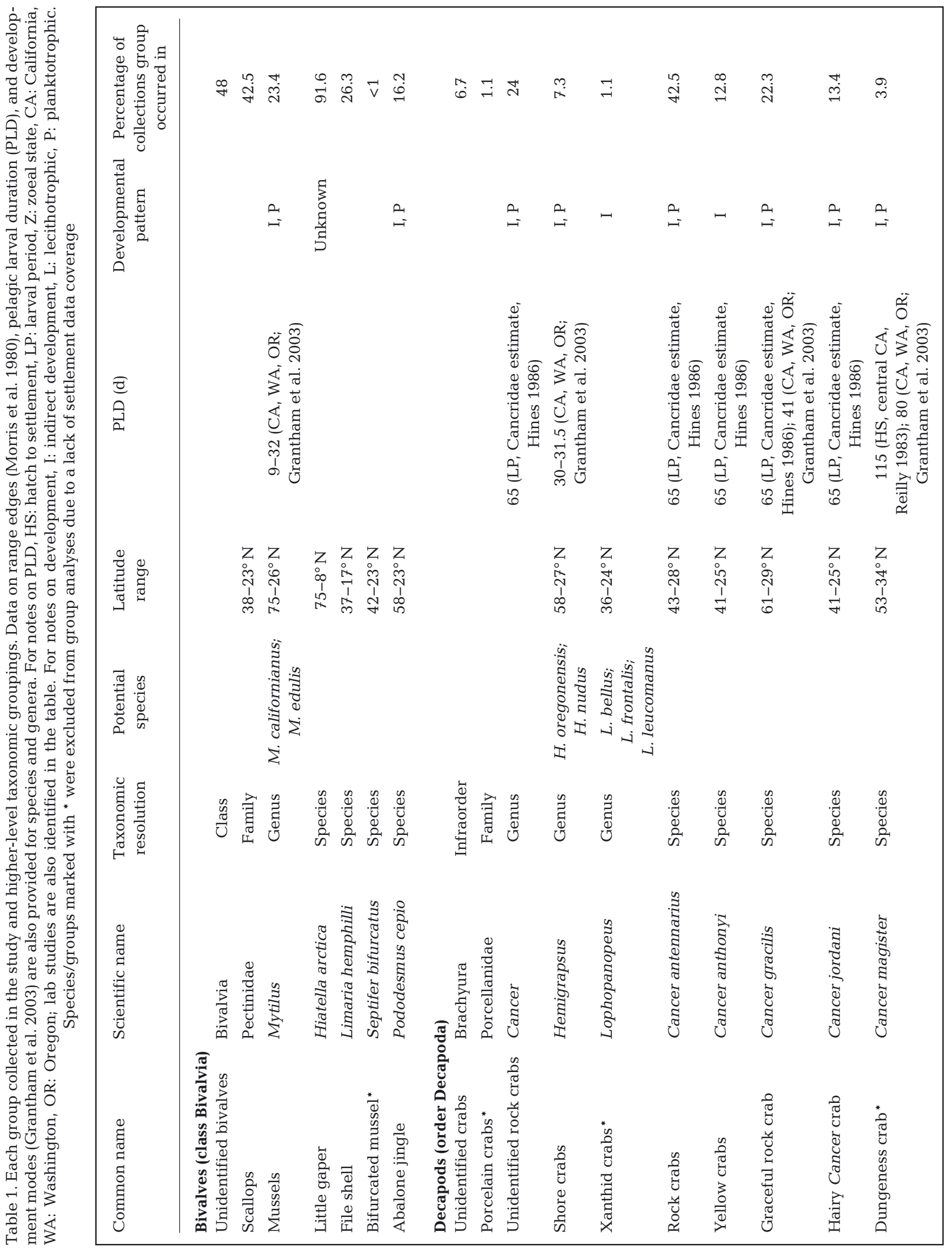




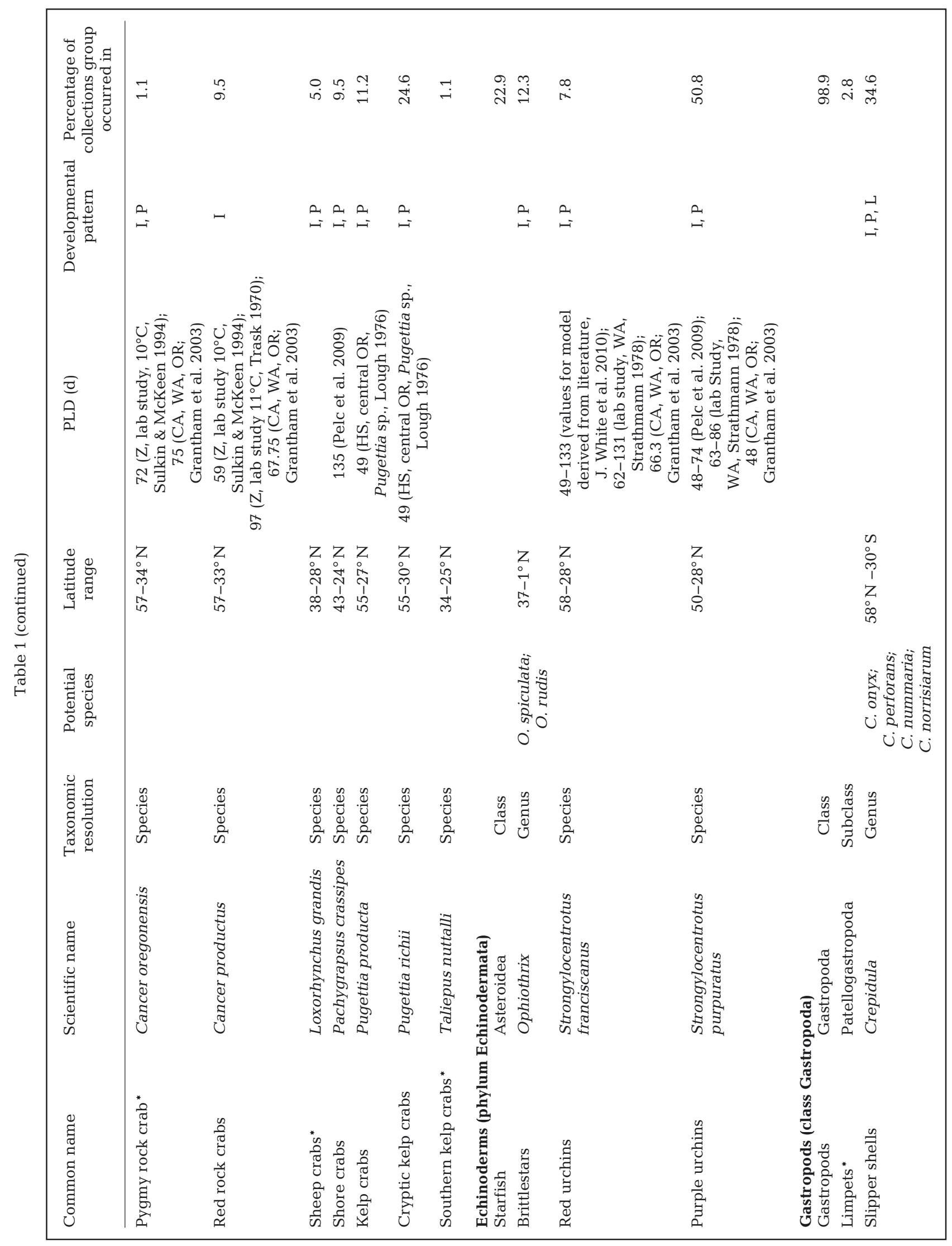




\section{Analysis}

Analysis was carried out using R (R Development Core Team 2012) and installed packages including nlme (Pinheiro et al. 2010), ggplot2 (Wickham 2009), and BiodiversityR (Kindt \& Coe 2005). We first explored general settlement patterns by determining whether daily settlement rates for each collection period were influenced by year or taxonomic grouping using a linear mixed-effects model. An immediate impact of taxonomic resolution was the lack of observations over the sampling period for some groups, which led to issues with model convergence and interpretation of results; for this reason, analyses for specific groups were only carried out for the 23 groups (out of 31 total) that were observed in greater than $5 \%$ of collections. Of these, 18 groups were observed in at least $10 \%$ of the collections, and 13 were observed in at least $20 \%$ of the collections (Table 1). Since significant interactions were noted between years and groups, we fitted models for each group to consider simple main effects (Winer et al. 1991). Main effects and interactions among year and group were considered as fixed effects, and a random effect for site was also included in the model to account for the lack of independence in measurements taken at the same site. The lack of independence in measurements taken over time was also accounted for by fitting a Gaussian correlation structure to the errors across time for each site. To meet model assumptions regarding normality and homogeneity of residuals, we regressed log (settlement + 0.02) against year and group to account for 0 measurements obtained for some groups in some collection periods; 0.0196 equaled the smallest non-0 per day settlement rate that we recorded. Significance of model parameters was examined by comparing nested models fit by maximum-likelihood methods using a likelihood-ratio test (Zuur et al. 2009).

In order to explore the effect of front movement across the study area, we followed Selkoe et al. (2006) in hypothesizing that differences in water temperature across the sites indicated the position of the fluctuating boundary between the 2 water masses. Due to the potential for rapid movement of the front, we examined temperature data across the sites at midnight for each day to determine a daily position of the boundary between water masses. For each day we calculated the absolute difference in temperature between adjacent collection sites and assigned the boundary position to a location between the 2 sites with the largest temperature difference (Fig. 1). We classified sites to the west of this bound- ary position as west of the front and those to the east of this point as east of the front. Including temperature data from the San Miguel and Anacapa sites in our calculations allowed us to consider the possibility that the boundary between water masses was not located along the coast of Santa Cruz Island. These sites are $60 \mathrm{~km}$ apart and located to west and east, respectively (Fig. 1). By using sites beyond the east and west extremes of the settlement array, we were able to further verify whether all sites sampled were on one side of the boundary or the other. If the boundary fell between either the Anacapa site and the farthest east Santa Cruz Island site, or conversely between the San Miguel and the farthest west sites, then the entire collection array was considered to be east and west of the boundary, respectively. In the case of missing temperature data, sites with settlement data that existed between sites with known temperature data may be classified as being on the wrong side of the front. However, we had total temperature coverage of sites with settlement data $78 \%$ of the time and $>80 \%$ coverage $94 \%$ of the time. Restricting our analyses by temperature coverage (>80\% coverage) did not qualitatively change our results.

After estimating the position of the front, we calculated for each collection period the proportion of sampling days that each site was west of our estimated frontal boundary and thus exposed to larvae from western sources (western larval pool index [WLP], following Selkoe et al. 2006). To consider the relationship between the WLP measure and other potential predictors of settlement or diversity, we carried out several analyses. We regressed the longitude of the boundary between the 2 water masses against month (considered a factor in the model) and WLP against mean temperature for each collection period. In order to determine whether WLP differed due to location along the coast, as we would expect if the index captured the movement of the 2 water masses, we regressed WLP against the longitude of the sites. We also regressed WLP against all possible combinations of longitude, mean temperature, and collection month (month when settlement collector was deployed) to determine relationships among these measures.

We next considered the influence of WLP on settlement for both levels of taxonomic grouping. Using the same model structure (random factor fit included for site, Gaussian correlation structure fit to the errors within each site over time), we regressed log (settlement+0.02) for each group against WLP. To compare the predictive ability of WLP to other fac- 
tors, we used the same model structure to analyze the influence of longitude and mean temperature during the collection period on settlement. Multiple regressions were also used to consider the influence of mean temperature, longitude, and WLP simultaneously on settlement; this exercise required a reduced dataset to account for any missing temperature data. Optimal model parameters were selected by comparing nested models fit by maximum-likelihood methods using likelihood-ratio tests (Zuur et al. 2009).

We also explored how WLP impacted the diversity of settlers using all collected data (no groups excluded). Given the varying levels of taxonomic resolution in our dataset, we considered how WLP impacted diversity of (1) all groups (ignoring differences in taxonomic resolution), (2) only organisms identified to the species level, (3) only crabs of the genus Cancer, and (4) super-groups. Using the total counts for of each of the groupings for each collection period, Shannon's diversity index was calculated for each collection period and regressed against WLP. The number of days of exposure and number of replicate brush pairs were also included in the model to account for potential effects of sampling on diversity. Site was again considered a random effect, and the relationship among residuals at each site over time was modeled using a Gaussian structure. The predictive ability of WLP on settlement diversity was again compared to longitude and mean temperature during the collection period using the same model structure, and multiple regression procedures were used to compare the simultaneous impacts of these factors. Significance of model parameters was again examined by comparing nested models fit by maximumlikelihood methods using likelihood-ratio tests (Zuur et al. 2009). In order to determine the usefulness of these models in predicting settlement and settler diversity, $R^{2}$ values were also calculated using methods developed for mixed models (Edwards et al. 2008).

\section{RESULTS}

\section{Interannual patterns in settlement}

Invertebrate settlement varied significantly between the 2 years and among taxonomic groups (Fig. 2). Average daily settlement for all sampled groups (mean $\pm \mathrm{SE}$ of all sites and collection periods) was significantly greater in 2009 compared to 2008 (2008: $1.58 \pm 0.19$ organisms $\mathrm{d}^{-1}$ collector $^{-1} ; 2009$ : $3.32 \pm 0.36$ ). Approximately half of the groups showed

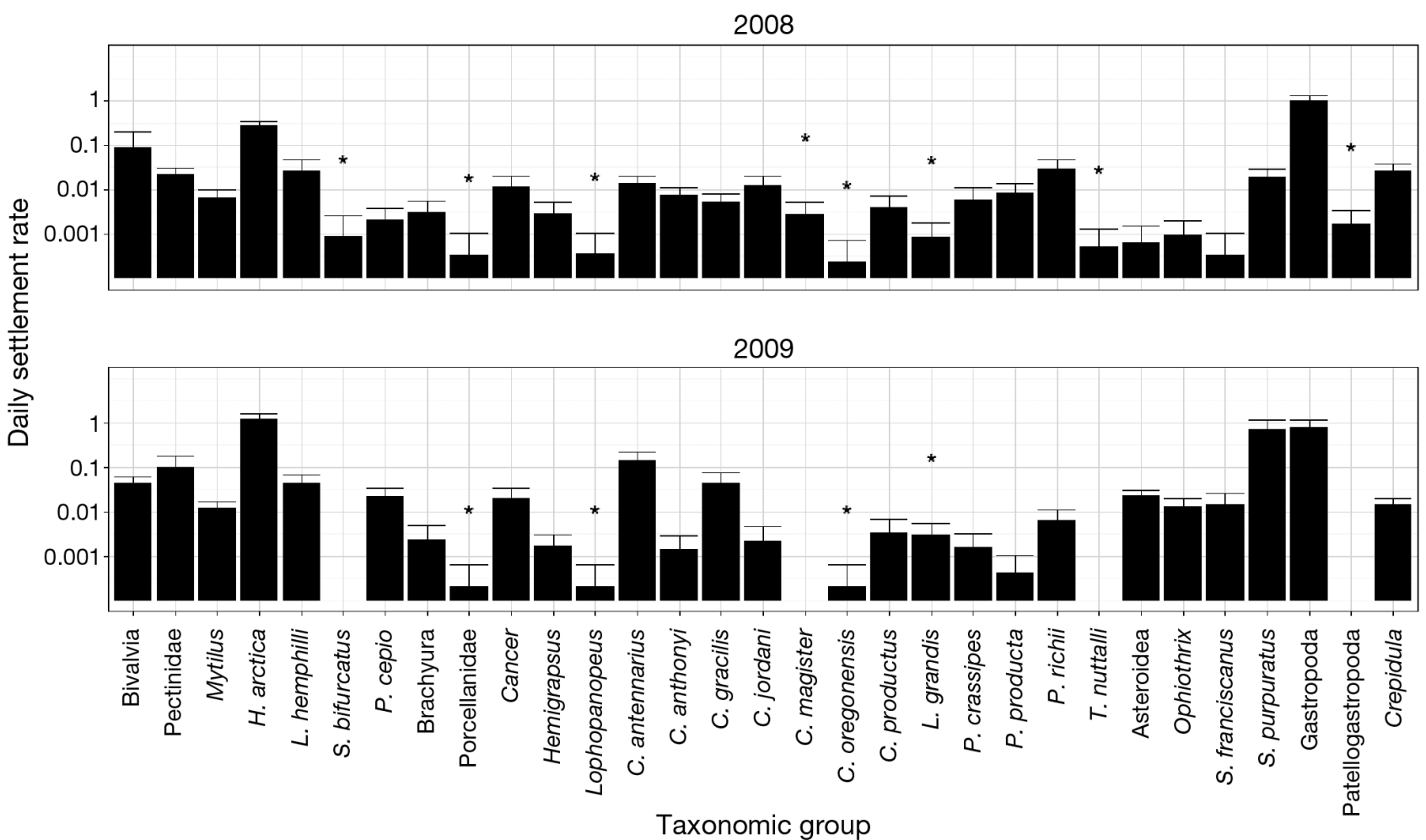

Fig. 2. Mean settlement rates (number of settlers per collector pair per day) for each taxonomic group across all sites for each year. Bars represent upper 95\% confidence intervals. Full group names are given in Table 1. Species/groups marked with * were excluded from further group analyses due to a lack of settlement data 
significantly different settlement rates between the 2 years (Table 2). The direction of these changes also differed among years. For example, higher settlement rates were observed for all echinoderms in 2009, but some decapods (Cancer anthonyi, C. jordani, Pachygrapsus crassipes, Pugettia sp.) had lower settlement in 2009 while others (C. antennarius) had higher settlement that year (Table 2). Analysis of the supergroups also revealed differences among years and groups. Higher overall settlement in 2009 was driven largely by bivalves and echinoderms, both of which had significantly greater settlement in 2009. In contrast, there was no significant difference among years for gastropods or decapods.

Table 2. Results from linear mixed models investigating how settlement rates differed between the 2 study years for each taxonomic group and super-groups. p-values are from comparing nested models fit by maximum likelihood and coefficients are from models fit using restricted maximumlikelihood methods. Bold font denotes significance at $\mathrm{p}=$ 0.05 level

\begin{tabular}{|c|c|c|c|}
\hline Taxonomic group & $\begin{array}{c}\text { Difference } \\
\text { between } 2009 \\
\text { and } 2008 \text { (model } \\
\text { coefficient) }\end{array}$ & l & $\mathrm{p}$ \\
\hline Bivalves & 1.096 & 31.400 & $<0.001$ \\
\hline Bivalvia & 0.049 & 0.137 & 0.711 \\
\hline Pectinidae & 0.344 & 6.413 & 0.011 \\
\hline Mytilus & 0.173 & 4.145 & 0.042 \\
\hline Hiatella arctica & 1.184 & 34.891 & $<0.001$ \\
\hline Limaria hemphilli & 0.171 & 1.244 & 0.265 \\
\hline Pododesmus cepio & 0.324 & 6.223 & 0.013 \\
\hline Decapods & 0.004 & $<0.001$ & 1.000 \\
\hline Brachyura & -0.028 & 0.295 & 0.587 \\
\hline Cancer & 0.081 & 0.412 & 0.521 \\
\hline Hemigrapsus & -0.026 & 0.407 & 0.523 \\
\hline Cancer antennarius & 0.781 & 7.935 & 0.005 \\
\hline Cancer anthonyi & -0.169 & 10.712 & 0.001 \\
\hline Cancer gracilis & 0.369 & 3.563 & 0.059 \\
\hline Cancer jordani & -0.215 & 11.831 & 0.001 \\
\hline Cancer productus & -0.033 & 0.513 & 0.474 \\
\hline Pachygrapsus crassipes & -0.120 & 4.174 & 0.041 \\
\hline Pugettia producta & -0.183 & 15.438 & $<0.001$ \\
\hline Pugettia richii & -0.310 & 7.177 & 0.007 \\
\hline Echinoderms & 1.391 & 9.186 & 0.002 \\
\hline Asteroidea & 0.451 & 11.930 & 0.001 \\
\hline Ophiothrix & 0.220 & 7.013 & 0.008 \\
\hline $\begin{array}{l}\text { Strongylocentrotus } \\
\text { franciscanus }\end{array}$ & 0.188 & 8.904 & 0.003 \\
\hline $\begin{array}{l}\text { Strongylocentrotus } \\
\text { purpuratus }\end{array}$ & 1.284 & 10.515 & 0.001 \\
\hline Gastropods & -0.046 & 0.075 & 0.784 \\
\hline Gastropoda & -0.037 & 0.047 & 0.828 \\
\hline Crepidula & -0.163 & 2.744 & 0.098 \\
\hline
\end{tabular}

\section{WLP over space and time}

Water temperature, which we here attribute to both seasonal variability and front movement, showed significant variation over the $2 \mathrm{yr}$ of the study, ranging from a minimum $9.8^{\circ} \mathrm{C}$ to a maximum of $21.5^{\circ} \mathrm{C}$. The daily temperature gradient across our sites during the $2 \mathrm{yr}$ of sampling ranged from 0.63 to $6.76^{\circ} \mathrm{C}$, with a range of $>1^{\circ} \mathrm{C}$ occurring over $99 \%$ of the time. Similarly, the largest absolute temperature among adjacent sites (which determined the boundary longitude according to our algorithm) varied from 0.15 to $6.76^{\circ} \mathrm{C}$ and was over $1^{\circ} \mathrm{C} 87 \%$ of the time.

According to our method for calculating the boundary longitude between the water masses, the longitude of the front varied greatly throughout the study period (Fig. 3). Although front position was significantly correlated with month $\left(F_{11,371}=4.30, \mathrm{p}<0.01\right)$, month only explained $11 \%$ of the variation in the position of the boundary between water masses during our sampling periods. The mean temperature during each collection period was also correlated with WLP (coefficient: $-0.08, F_{1,151}=87.50, \mathrm{p}<0.01$ ), with variation in temperature explaining $33 \%$ of the variation in WLP. This relationship was expected, as front movement may lead to changes in temperature. As expected, sites with higher mean temperatures had lower WLP measures since they were more commonly exposed to warm water on the eastern side of the front. However, it should be noted that WLP focused on the difference in temperature between adjacent sites and not actual temperature, offering a reason why these 2 measures may be related but not the same. WLP was also negatively related to longitude (Fig. 4), with western sites spending a significantly greater proportion of time in the western larval pool (coefficient: $-0.012, F_{1,177}=47.98$, $p<0.01$; Fig. 4), but longitude only explained $21 \%$ of the variation in WLP. Mean temperature during the collection period, month of collection, and site longitude together explained $74 \%$ of the variation in WLP, and any 2 of these variables explained over $54 \%$ of the variation in WLP. Due to the amount of correlation within this group of variables, we focused the rest of our analysis on the power of WLP to explain settlement patterns and offer a mechanism by which other factors (e.g. mean temperature during the collection period and location of collecting site) influence settlement. We then compared the predictive ability of WLP to that of longitude and mean temperature during the collection period and used multiple regression procedures to consider the combined impact of these factors. 


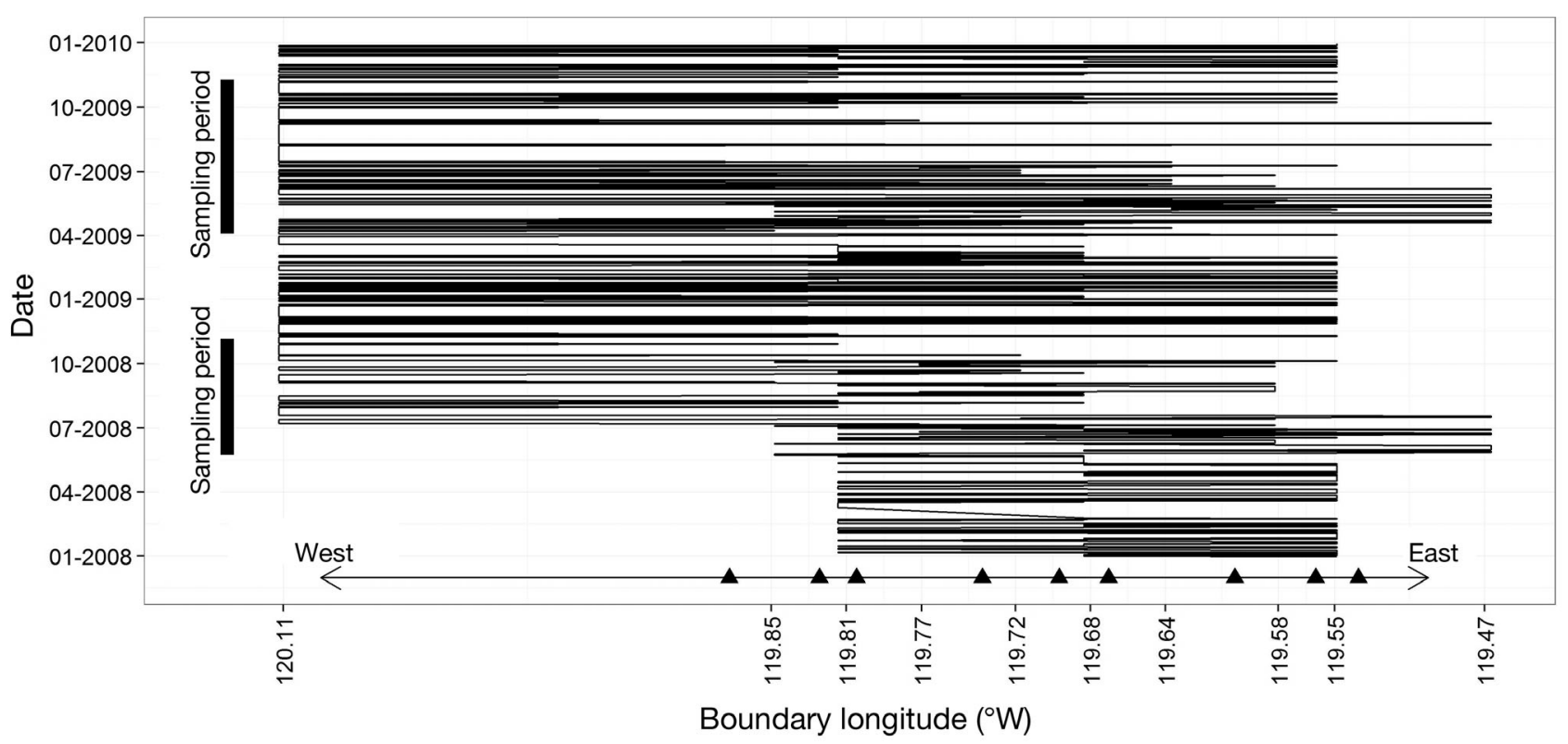

Fig. 3. Estimates of daily position of the front (i.e. location with largest temperature difference among adjacent sites) as identified by the algorithm for 2008 and 2009. Daily estimates are connected by lines to demonstrate patterns in front movement. Sampling periods for each year are marked. Triangles on the W-E line correspond to collection points along Santa Cruz Island

\section{Impact of WLP on settlement abundance and diversity}

Analyses indicated that WLP was a significant predictor of settlement rates for 13 of our taxonomic groups (Table 3). For these groups, WLP explained between 2.8 and $13.7 \%$ of the variation in settlement rates. By comparison, longitude of collection sites was only a significant predictor for settlement of 6 groups and never explained more than $4.3 \%$ of the variation in settlement. Settlement in 4 groups was significantly impacted by both longitude and WLP, with WLP being a better predictor of settlement in all of these

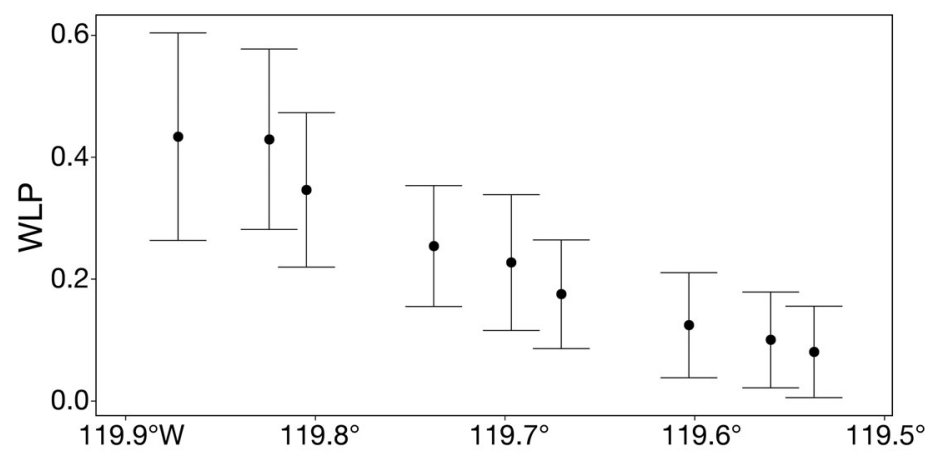

Fig. 4. Mean western larval pool index (WLP) measures (estimate of the proportion of time a site was exposed to the western water mass for each sampling period) for each site ordered by longitude. Bars represent $95 \%$ confidence intervals groups. The mean temperature during collection periods alone explained variation in the settlement of 12 groups, with explanatory power ranging from 2.6 to $31.3 \%$. Several noticeably strong patterns existed in this dataset, with decreases in temperature explaining $31.3 \%$ of settlement variation in C. antennarius, $27.0 \%$ of the variation in unidentified Cancer species, and $26.0 \%$ of settlement variation in C. gracilis. Settlement in 9 groups was significantly impacted by both temperature and WLP, with WLP being a better predictor of settlement in 5 of these groups.

All bivalves and gastropods that were influenced by WLP were positively associated with the proportion of time spent in the eastern water mass (i.e. lower WLP). Similarly, settlement of all crab species increased with exposure to the western water mass, but echinoderms showed mixed responses to WLP, with some groups not being impacted by WLP and others having positive and negative correlations.

Multiple regression analyses demonstrated that interactions among WLP, temperature, and longitude differed among groups (Table 3). WLP was a significant predictor of settlement for 10 groups, while temperature was a significant predictor for 11 groups and longitude for 6 . In 4 groups, both temperature and WLP were retained, indicating that both of these factors can influence settlement.

WLP also had a significant impact on settlement rates for 3 out of 4 of the taxonomic super-groups 


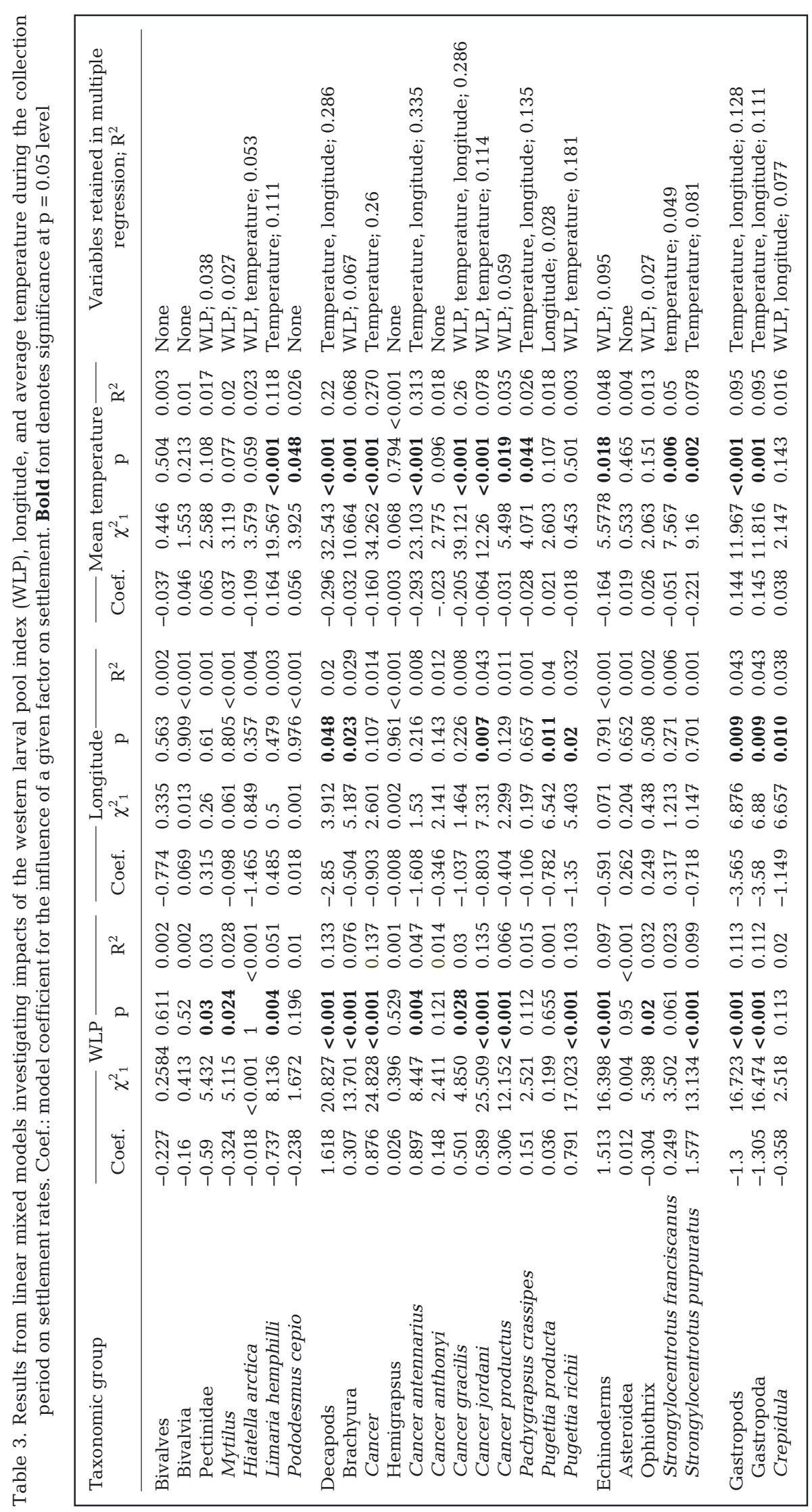

(Table 3). Echinoderm and decapod settlement were significantly and positively associated with the proportion of time spent in the western water mass ( $p<0.01)$, while gastropod settlement was significantly greater when a site had a higher proportion of time in the eastern water mass. For these super-groups, $\mathrm{R}^{2}$ values indicated that WLP explained over $9.5 \%$ of the variation in settlement. Bivalves did not appear to be influenced by WLP (i.e. changes in position of the front in relation to sites did not impact bivalve settlement). For comparison, longitude of collection sites was only a significant predictor for settlement of gastropods and decapods, explaining 4.3 and $1.9 \%$ of the variation in settlement, respectively. The mean temperature during collection periods alone explained variation in the settlement of decapods (22\%), echinoderms $(4.7 \%)$, and gastropods $(9.5 \%)$, thus predicting settlement in the same supergroups as WLP but with a wider range of explained variation.

Although not shown here, relationships between WLP and settlement abundance were qualitatively similar at the group and super-group level even if additional constraints were considered in determining the position of the frontal boundary (i.e. requiring a minimum absolute difference between sites or a minimum range of temperatures across the study sites to infer front location). WLP was also found to impact settlement if, instead of settler abundance, we focused on the presence of settlers via logistic regression. These consistent results suggest that our temperature-based method for 
determining boundary position is robust and that a clear relationship exists between front movement and settlement rates.

Analysis of settler diversity indicated that WLP had a significant positive effect on settlement diversity regardless of taxonomic resolution. Increased WLP was associated with higher diversity of all sampled groups (model coefficient: $2.125, \chi^{2}{ }_{1}=7.766, p=0.005$, $30.9 \%$ of variation in diversity explained), of only groups identified to species level (model coefficient: $2.492, \chi^{2}{ }_{1}=21.798, \mathrm{p}<0.001,29.7 \%$ of variation in diversity explained), of only Cancer crabs (model coefficient: $1.824, \chi^{2}{ }_{1}=15.458, \mathrm{p}<0.001,23.5 \%$ of variation in diversity explained), and of super-groups (model coefficient: $2.49, \chi^{2}{ }_{1}=24.30, \mathrm{p}<0.01,19 \%$ of variation in diversity explained). Diversity decreased with longitude at every analyzed level, and longitude was a significant predictor for diversity of all sampled groups, organisms classified to the species level, and crabs from the genus Cancer. Longitude consistently did not explain more variation in settlement than WLP $(30.9,28.8$, and $12.5 \%$ of variation in settlement diversity explained for all groups, species, and Cancer crabs, respectively) and was not a significant predictor at the super-group level. Mean temperature during the collection period was a significant predictor of diversity at all levels of analyses, with increases in temperature leading to lower levels of diversity. The level of variation in settlement explained by temperature $(28.1,28.8,28.5$, and $22 \%$ for all groups, species, Cancer crabs, and super-groups, respectively) was a better predictor than WLP at some levels of taxonomic resolution but was less predictive at others. Multiple regression analyses again indicated complex relationships among WLP, temperature, and longitude. The diversity of all sampled groups, only species, and Cancer crabs were best predicted by temperature and longitude, which explained 32.3, 38.8 , and $32.8 \%$ of the variation in diversity, respectively. At the super-group level, WLP and temperature were retained in the model to explain $29.1 \%$ of the variation in settlement.

\section{DISCUSSION}

Here we have demonstrated that variation in settlement patterns of some marine invertebrates over relatively small spatial scales along a single island can be explained by front movement patterns that we characterized by analyzing differences in daily temperatures among sites. Over the 2 yr of our study, settlement rates of key taxonomic groups were strongly correlated with the proportion of time that a given location spent under the influence of a relatively colder water mass versus a warmer water mass (our WLP measure). We also found a positive relationship between the proportion of days that a site was exposed to cold water and higher settlement diversity, likely due to increased settlement by echinoderms and decapods. Past work demonstrating major temperature differences between the 2 water masses that converge along Santa Cruz Island (Harms \& Winant 1998, Broitman et al. 2005, Selkoe et al. 2006, Woodson et al. 2012) suggests that our observed temperature differences correspond to the boundary, or front, between these 2 masses, with cold water originating from the western California Current and warmer water originating from the Southern California Eddy. Qualitative comparisons of our measure of boundary position and sea surface temperature imagery also suggest that our algorithm is accurately predicting the position of the front (for example see Fig. 1). The positive relationship between diversity and our frontal index may be explained by the fact that our study sites typically shifted from receiving water primarily from the eastern water mass (low WLP) to receiving water from both water masses (intermediate WLP; Fig. 4). Areas with exposure to both water masses (those with intermediate WLP) likely receive larvae from both water masses in sufficient quantity to sustain populations and thus be local diversity hotspots; we suspect sites primarily exposed to the western water mass (high WLP) would have lower overall diversity and that a unimodal (humped) relationship actually exists between diversity and frontal movement. Future studies including sampling sites that are primarily exposed to the western water mass would allow a test of this hypothesis.

By explaining temperature variation as a result of the movement of water masses, our findings link the effects of temperature and oceanographic patterns by focusing on front movement. Previous studies have demonstrated that temperature may influence factors including recruitment, adult abundance, and nutrients at Santa Cruz Island (Broitman et al. 2005, Blanchette et al. 2006, Selkoe et al. 2006), and a study of crab settlement in northern California found that both colder and warmer water respectively resulted in increases in settlement linked to the 'residence' of different species in those water masses (Wing et al. 1995). Similarly, we found the average temperature during collection periods to be an important predictor of settlement for 12 of our taxonomic groups; 9 of these were also influenced by frontal movement. 
Temperature also predicted settlement in the same 3 super-groups as frontal index. This suggests that a portion of the influence of temperature on settlement may relate to frontal movement. Previous settlement studies in the Santa Barbara Channel and northern California have also found an association between settlement of urchins and crabs associated with longshore flow of surface water (Ebert et al. 1994, Wing et al. 2003, Mace \& Morgan 2006). Building on this work, we demonstrated that the diversity of invertebrate settlement is significantly different at the site level based on which side of the front a particular site is on over time.

These results offer a mechanism to explain the spatial patterns and associations with factors such as temperature that are commonly observed in regards to the settlement of individual groups and total settler diversity. They also suggest that boundaries between biogeographic regions may be variable in space and time with important repercussions for settlers and thus potentially community diversity. Like Watson et al. (2010), we found a directionality in larval settlement related to oceanographic circulation patterns, but in our analyses, this directionality was directly related to the movement of a dynamic front and resulting exposure of sites to different water masses with different larval pools. Many of our sampled groups have documented ranges that span our sampling sites at Santa Cruz Island, yet our results suggest that settlement of these groups along Santa Cruz Island may be closely tied to source populations on either side of the front due to factors such as pelagic larval duration and proximity to adjacent sites. This may also have important implications for the ability of populations to respond to environmental variation, as source population may differ in their response to factors such as temperature. These results are also consistent with particle modeling and genetic studies of other invertebrates and fish in the region that show that both settlement and genetic relationships among populations are influenced by water movement within the Santa Barbara Channel (Selkoe et al. 2006, C. White et al. 2010). Our results are also consistent with findings from other studies focusing on crabs and echinoderms that noted high interannual variability in settlement rates (Schroeter et al. 2009).

Our results therefore offer the ability to consider the impact of larval source and exposure directly on settlement. The relationship between mean temperature during the collection period and frontal movement may explain why these metrics are similar in how they correlate to settlement. However, while our frontal measure focuses on relative temperature dif- ferences among sites to predict water movement and potential for larval delivery, measures of mean temperature over various time scales may also offer insight as to how changing water conditions directly influence larval survival during settlement or very early post-settlement, suggesting that these 2 measures may both be useful at predicting community diversity by focusing on larval delivery (WLP) and post-settlement survival or growth at a site (temperature). Additional species- and group-specific factors such as spawning season and species-specific settlement cues may also interact with front movement to further explain recruitment and settlement dynamics.

By combining a higher temporal and spatial resolution of invertebrate settlement patterns with a robust and concise metric for explaining the position of the front in time, our results build significantly on previous studies conducted in the Santa Barbara Channel (Blanchette et al. 2006, Selkoe et al. 2006, Broitman et al. 2008, Caselle et al. 2010, Woodson et al. 2012). The algorithmic method used here to approximate frontal boundary may be useful in other systems due to its relative ease of application and the wide availability of both in situ and remotely sensed temperature data (Broitman et al. 2005, 2008, Blanchette et al. 2006, Wilson et al. 2008, Caselle et al. 2010). Using in situ data also removes issues with cloud cover being associated with SST and thus obstructing remotely sensed SST imagery (Woodson et al. 2012). Our method could also be applied to other variables that are commonly measured and that differentiate water masses (e.g. salinity). This computational method also builds on and improves previous attempts to use temperature to determine boundary location by removing subjectivity inherent in manually (i.e. visually) comparing satellite images (Selkoe et al. 2006). Given available computing power, this method should increase the resolution and speed at which boundaries among water masses may be identified and enable further exploration of boundary movement. We propose that the sampling and analytical techniques used here for Santa Cruz Island could be utilized over a larger area to describe settlement trends across the greater region of the Southern California Bight or in other regions where water masses meet. Clearly resolving the driver of these patterns may clarify how future changes in oceanographic patterns or local environmental disasters may influence regional patterns in diversity.

We found that our metric of frontal movement was related to settlement and diversity across a variety of constraints imposed and levels of taxonomic group- 
ings. However, our multi-scale analysis also demonstrates the value of increasing taxonomic resolution. For example, although we found that the settlement of multiple bivalves was related to WLP, no relationship existed between the WLP metric and overall settlement of bivalves because some of the most common species in that group were not influenced by WLP and because differences existed in the directional relationship between WLP and settlement. Resolving individuals to the species level may clearly offer more insight on diversity. However, we also observed relationships between WLP and the combined settlement of species considered in higher taxonomic groups.

These front-driven differences in settlement rates may have management implications. We have demonstrated that sites that receive water from both sides of the front have higher taxonomic diversity. These sites may also have higher genetic diversity within species, as front movement has previously been linked to genetic breaks among populations (Selkoe et al. 2006). This suggests that front movement may contribute to the formation of diversity hotspots that may be prime candidates for protection. Managers and others may also be able to use these methods to better predict delivery of these groups along the island's coast based on widely available oceanographic data. Understanding the impact of oceanographic patterns on settlement rates and diversity may be essential to fisheries conservation and management and choosing where and when to place marine protected areas (Schroeter et al. 2009). The ability of our frontal index to predict settlement in broader taxonomic groupings may also be useful for multi-species management applications. For example, in California, the crab fisheries are regulated for Cancer magister alone versus for $C$. anthonyi, $C$. antennarius, and C. productus combined.

We demonstrated in this study that we were able to characterize a major oceanographic feature using only in situ seawater temperature and that movement in this feature had direct impacts on the settlement of larval invertebrates. Our study provides a simple explanation for how dynamic boundaries between water masses may affect settlement and by extension biological diversity and offers a mechanism by which other factors such as temperature may influence these measures. In the future, expanding the type of analysis outlined here to a larger region and over longer continuous time periods will provide a better understanding of community diversity and formation beyond the single-island scale. Similarly, using this type of analysis could aid in understanding how temporally varying processes such as delivery, settlement probability, and post-settlement mortality interact to determine diversity in communities composed of species with pelagic larvae. Results from this study and its extensions, along with methods developed herein, may also inform conservation efforts within the greater California Current System and in other regions where ocean currents meet. In general, this work demonstrates the importance of considering variation in large-scale drivers of diversity, especially for communities that reside near potential biogeographic breaks, and demonstrates that variation in these large-scale patterns may result in important differences among communities on a much smaller spatial scale.

Acknowledgements. We thank the Gaines, Washburn, Shears, and Caselle lab groups for their input on this project and manuscript and Jenny Dugan for assistance with identifying decapod larvae. Thanks to P. Carlson, K. Davis, A. Parsons-Field, and many students for help in the field; C. Gotschalk for processing temperature data; and M. Kibby for excellent captaining skills. Maps were made with data provided via Natural Earth, and sea surface temperature data were compiled by the Scripps Photobiology Group. The manuscript was improved by comments from M. McManus and L. Washburn. Funding or in-kind support was provided by the California Department of Fish and Game, the Montrose Settlements Restoration Trust, the Channel Islands National Marine Sanctuary, and the Partnership for Interdisciplinary Studies of Coastal Oceans (PISCO), which is supported primarily by the Gordon and Betty Moore Foundation and the David and Lucile Packard Foundation. This is PISCO contribution number 438.

\section{LITERATURE CITED}

Belkin IM, Cornillon PC, Sherman K (2009) Fronts in large marine ecosystems. Prog Oceanogr 81:223-236

> Bjorkstedt EP, Rosenfeld LK, Grantham BA, Shkedy Y, Roughgarden J (2002) Distributions of larval rockfishes Sebastes spp. across nearshore fronts in a coastal upwelling region. Mar Ecol Prog Ser 242:215-228

Blanchette CA, Gaines SD (2007) Distribution, abundance, size and recruitment of the mussel, Mytilus californianus, across a major oceanographic and biogeographic boundary at Point Conception, California, USA. J Exp Mar Biol Ecol 340:268-279

> Blanchette C, Broitman B, Gaines S (2006) Intertidal community structure and oceanographic patterns around Santa Cruz Island, CA, USA. Mar Biol 149:689-701

> Bradbury IR, Snelgrove PVR (2001) Contrasting larval transport in demersal fish and benthic invertebrates: the roles of behaviour and advective processes in determining spatial pattern. Can J Fish Aquat Sci 58:811-823

Brante A, Fernández M, Viard F (2012) Phylogeography and biogeography concordance in the marine gastropod Crepipatella dilatata (Calyptraeidae) along the southeastern Pacific coast. J Hered 103:630-637 
Broitman BR, Blanchette CA, Gaines SD (2005) Recruitment of intertidal invertebrates and oceanographic variability at Santa Cruz Island, California. Limnol Oceanogr 50: 1473-1479

Broitman BR, Blanchette CA, Menge BA, Lubchenco J and others (2008) Spatial and temporal patterns of invertebrate recruitment along the west coast of the United States. Ecol Monogr 78:403-421

Caroll JC, Winn RN (1989) Species profiles: life histories and environmental requirements of coastal fishes and invertebrates (Pacific Southwest). Brown rock crab, red rock crab, and yellow crab. U.S. Fish and Wildlife Service Biol Rep 82(11.117). U.S. Army Corps of Engineers TR-EL-824. U.S. Army Corps of Engineers, Vicksburg, MS, and USFWS, Washington, DC

Carr MH, Neigel JE, Estes JA, Andelman S, Warner RR, Largier JL (2003) Comparing marine and terrestrial ecosystems: implications for the design of coastal marine reserves. Ecol Appl 13:90-107

Caselle JE, Wilson JR, Carr MH, Malone DP, Wendt DE (2010) Can we predict interannual and regional variation in delivery of pelagic juveniles to nearshore populations of rockfishes (genus Sebastes) using simple proxies of ocean conditions? Calif Coop Ocean Fish Invest Rep 51: 91-105

> Chainho P, Lane MF, Chaves ML, Costa JL, Costa MJ, Dauer DM (2007) Taxonomic sufficiency as a useful tool for typology in a poikilohaline estuary. Hydrobiologia 587: 63-78

Cowen RK, Paris CB, Srinivasan A (2006) Scaling of connectivity in marine populations. Science 311:522-527

> Ebert TA, Schroeter SC, Dixon JD, Kalvass PE (1994) Settlement patterns of red and purple sea urchins (Strongylocentrotus franciscanus and $S$. purpuratus) in California, USA. Mar Ecol Prog Ser 111:41-52

Eckert GL (2003) Effects of the planktonic period on marine population fluctuations. Ecology 84:372-383

> Edwards LJ, Muller KE, Wolfinger RD, Qaqish BF, Schabenberger $\mathrm{O}$ (2008) An $\mathrm{R}^{2}$ statistic for fixed effects in the linear mixed model. Stat Med 27:6137-6157

- Fisher R, Leis JM, Clark DL, Wilson SK (2005) Critical swimming speeds of late-stage coral reef fish larvae: variation within species, among species and between locations. Mar Biol 147:1201-1212

> Gaines SD, Gaylord B, Largier JL (2003) Avoiding current oversights in marine reserve design. Ecol Appl 13:32-46

Gaines SD, Lester SE, Eckert GL, Kinlan BP, Sagarin RD, Gaylord B (2009) Dispersal and geographic ranges in the sea. In: Witman J, Roy K (eds) Marine macroecology. University of Chicago Press, Chicago, IL, p 227-249

> Gaylord B, Gaines SD (2000) Temperature or transport? Range limits in marine species mediated solely by flow. Am Nat 155:769-789

Gleason LU, Burton RS (2013) Phenotypic evidence for local adaptation to heat stress in the marine snail Chlorostoma (formerly Tegula) funebralis. J Exp Mar Biol Ecol 448: 360-366

Grantham BA, Eckert GL, Shanks AL (2003) Dispersal potential of marine invertebrates in diverse habitats. Ecol Appl 13:108-116

Gunderson DR, Parma AM, Hilborn R, Cope JM and others (2008) The challenge of managing nearshore rocky reef resources. Fisheries 33:172-179

> Harms S, Winant CD (1998) Characteristic patterns of the circulation in the Santa Barbara Channel. J Geophys Res
103:3041-3065

> Hendershott MC, Winant CD (1996) Surface circulation in the Santa Barbara channel. Oceanography 9:114-121

> Hickey BM (1992) Circulation over the Santa Monica-San Pedro Basin and Shelf. Prog Oceanogr 30:37-115

Hines AH (1986) Larval patterns in the life histories of brachyuran crabs (Crustacea, Decapoda, Brachyura). Bull Mar Sci 39:444-466

Kelly MW, Sanford E, Grosberg RK (2012) Limited potential for adaptation to climate change in a broadly distributed marine crustacean. Proc R Soc Lond B Biol Sci 279: 349-356

Kindt R, Coe R (2005) Tree diversity analysis: a manual and software for common statistical methods for ecological and biodiversity studies. World Agroforestry Centre, Nairobi

- Kinlan BP, Gaines SD (2003) Propagule dispersal in marine and terrestrial environments: a community perspective. Ecology 84:2007-2020

> Leibold MA, Holyoak M, Mouquet N, Amarasekare P and others (2004) The metacommunity concept: a framework for multi-scale community ecology. Ecol Lett 7: 601-613

Leis JM, Carson-Ewart BM (1997) In situ swimming speeds of the late pelagic larvae of some Indo-Pacific coral-reef fishes. Mar Ecol Prog Ser 159:165-174

Lough RG (1976) Larval dynamics of the Dungeness crab, Cancer magister, off the central Oregon coast, 1970-71. Fish Bull 74:353-376

> Mace AJ, Morgan SG (2006) Biological and physical coupling in the lee of a small headland: contrasting transport mechanisms for crab larvae in an upwelling region. Mar Ecol Prog Ser 324:185-196

McLaughlin FA, Carmack EC, Macdonald RW, Bishop JKB (1996) Physical and geochemical properties across the Atlantic/Pacific water mass front in the southern Canadian Basin. J Geophys Res 101:1183-1197

> Morgan SG, Fisher JL, Miller SH, McAfee ST, Largier JL (2009) Nearshore larval retention in a region of strong upwelling and recruitment limitation. Ecology 90: 3489-3502

Morris RH, Abbott DP, Haderlie EC (1980) Intertidal invertebrates of California. Stanford University Press, Stanford, CA

O'Connor MI, Bruno JF, Gaines SD, Halpern BS, Lester SE, Kinlan BP, Weiss JM (2007) Temperature control of larval dispersal and the implications for marine ecology, evolution, and conservation. Proc Natl Acad Sci USA 104: 1266-1271

> Oey LY, Wang DP, Hayward T, Winant C, Hendershott M (2001) 'Upwelling' and 'cyclonic' regimes of the nearsurface circulation in the Santa Barbara Channel. J Geophys Res 106:9213-9222

Pelc RA, Warner RR, Gaines SD (2009) Geographical patterns of genetic structure in marine species with contrasting life histories. J Biogeogr 36:1881-1890

Pinheiro J, Bates D, DebRoy S, Sarkar D, R Development Core Team (2010) nlme: linear and nonlinear mixed effects models. http://CRAN.R-project.org/package=nlme

R Development Core Team (2012) R: a language and environment for statistical computing. R Foundation for Statistical Computing, Vienna

Reilly PN (1983) Dynamics of Dungeness crab, Cancer magister, larvae off Central and Northern California. Calif Dep Fish Game Bull 172:57-84 
Roesijadi G (1976) Descriptions of the prezoeae of Cancer magister Dana and Cancer productus Randall and the larval stages of Cancer antennarius Stimpson (Decapoda, Brachyura). Crustaceana 31:275-295

Schroeter SC, Page HM, Dugan JE, Culver CS and others (2009) Scales of variability in larval settlement within the Channel Islands National Marine Sanctuary and along the mainland coast. In: Proceedings of the Seventh California Islands Symposium Institute for Wildlife Studies, Arcata, CA, p 151-160

Selkoe KA, Gaines SD, Caselle JE, Warner RR (2006) Current shifts and kin aggregation explain genetic patchiness in fish recruits. Ecology 87:3082-3094

Smith DL, Johnson KB (1996) A guide to marine coastal plankton and marine invertebrate larvae. Kendall/Hunt Pub. Co., Dubuque, IA

Sorte CJB, Jones SJ, Miller LP (2011) Geographic variation in temperature tolerance as an indicator of potential population responses to climate change. J Exp Mar Biol Ecol 400:209-217

Strathmann R (1978) Length of pelagic period in echinoderms with feeding larvae from the Northeast Pacific. J Exp Mar Biol Ecol 34:23-27

Strathmann RR, Hughes TP, Kuris AM, Lindeman KC, Morgan SG, Pandolfi JM, Warner RR (2002) Evolution of local recruitment and its consequences for marine populations. Bull Mar Sci 70:377-396

Sulkin SD, McKeen G (1994) Influence of temperature on larval development of four co-occurring species of the brachyuran genus Cancer. Mar Biol 118:593-600

Timms LL, Bowden JJ, Summerville KS, Buddle CM (2013) Does species-level resolution matter? Taxonomic sufficiency in terrestrial arthropod biodiversity studies. Insect Conserv Divers 6:453-462

Tittensor DP, Mora C, Jetz W, Lotze HK, Ricard D, Berghe EV, Worm B (2010) Global patterns and predictors of marine biodiversity across taxa. Nature 466:1098-1101

> Trask T (1970) A description of laboratory-reared larvae of Cancer productus Randall (Decapoda, Brachyura) and a comparison to larvae of Cancer magister Dana. Crustaceana 18:133-146

Vanschoenwinkel B, de Vries C, Seaman M, Brendonck L (2007) The role of metacommunity processes in shaping invertebrate rock pool communities along a dispersal gradient. Oikos 116:1255-1266

Editorial responsibility: Alejandro Gallego, Aberdeen, UK
Ward JV, Stanford JA (1995) Ecological connectivity in alluvial river ecosystems and its disruption by flow regulation. Regul Rivers Res Manag 11:105-119

> Watson JR, Mitarai S, Siegel DA, Caselle JE, Dong C, McWilliams JC (2010) Realized and potential larval connectivity in the Southern California Bight. Mar Ecol Prog Ser 401:31-48

Watson JR, Hays CG, Raimondi PT, Mitarai S and others (2011) Currents connecting communities: nearshore community similarity and ocean circulation. Ecology 92: 1193-1200

White C, Selkoe K, Watson J, Siegel D, Zacherl D, Toonen $R$ (2010) Ocean currents help explain population genetic structure. Proc R Soc Lond B Biol Sci 277: 1685-1694

White JW, Botsford LW, Moffitt EA, Fischer DT (2010) Decision analysis for designing marine protected areas for multiple species with uncertain fishery status. Ecol Appl 20:1523-1541

Wickham H (2009) ggplot2: elegant graphics for data analysis. Springer, New York, NY

- Wilson JR, Broitman BR, Caselle JE, Wendt DE (2008) Recruitment of coastal fishes and oceanographic variability in central California. Estuar Coast Shelf Sci 79:483-490

Winer BJ, Brown DR, Michels KM (1991) Statistical principles in experimental design, 3rd edn. McGraw-Hill, New York, NY

> Wing SR, Botsford LW, Largier JL, Morgan LE (1995) Spatial structure of relaxation events and crab settlement in the northern California upwelling system. Mar Ecol Prog Ser 128:199-211

> Wing SR, Botsford LW, Morgan LE, Diehl JM, Lundquist CJ (2003) Inter-annual variability in larval supply to populations of three invertebrate taxa in the northern California Current. Estuar Coast Shelf Sci 57:859-872

Wolanski E, Hamner WM (1988) Topographically controlled fronts in the ocean and their biological influence. Science 241:177-181

Woodson CB, McManus MA, Tyburczy JA, Barth JA and others (2012) Coastal fronts set recruitment and connectivity patterns across multiple taxa. Limnol Oceanogr 57: 582-596

Zuur AF, Ieno EN, Walker NJ, Saveliev AA, Smith GM (2009) Mixed effects models and extensions in ecology with R. Springer Verlag, New York, NY

Submitted: January 10, 2014; Accepted: March 18, 2014 Proofs received from author(s): June 24, 2014 